\title{
Experimental and theoretical study on wax deposition and the application on a heat insulated crude oil pipeline in Northeast China
}

\author{
Dongxu Sun ${ }^{1,2}$, Zuoliang Zhu ${ }^{1}$, Zhiyong $\mathrm{Hu}^{1}$, and Ming $\mathrm{Wu}^{1, *}$ \\ ${ }^{1}$ College of Petroleum Engineering, Liaoning Shihua University, Fushun, Liaoning 113001, PR China \\ ${ }^{2}$ College of Pipeline and Civil Engineering, China University of Petroleum (East China), Qingdao, Shandong 266580, PR China
}

Received: 21 October 2019 / Accepted: 6 December 2019

\begin{abstract}
An experimental loop apparatus of heat insulated waxy crude oil pipeline was established to study the wax deposition behaviors. The effects of flow rate and ambient temperature on the thickness and wax content of deposition layer were investigated. A kinetic calculation model for the thickness and wax content of deposition layer in heat insulated crude oil pipeline was established based on the principle of molecular diffusion, aging and shear energy. The results calculated by the model are in good agreement with the experimental values. The wax deposition thickness of a heat insulated crude oil pipeline in different seasons and operation time in Northeast China was predicted according to the theoretical model, which was anticipated that can provide a scientific basis for formulating the wax removal cycle of the pipeline. The predicted results showed that the thickness of the wax deposition layer increases first and then decreases along the pipeline.
\end{abstract}
Abbreviations
$c_{\mathrm{p}} \quad$ Constant pressure specific heat capacity of crude oil, $\mathrm{J} /\left(\mathrm{kg}{ }^{\circ} \mathrm{C}\right)$
$C_{\mathrm{wb}}$
$\mathrm{C}_{\mathrm{ws}}$ Wax molecular concentration in oil, $\mathrm{kg} / \mathrm{m}^{3}$
$D_{\text {e }}$ Solubility of wax molecules in oil, $\mathrm{kg} / \mathrm{m}^{3}$ Effective diffusion coefficient of wax inside the deposition layer, $\mathrm{m}^{2} / \mathrm{s}$
$D_{\text {wo }} \quad$ Molecular diffusivity of wax in oil, $\mathrm{m}^{2} / \mathrm{s}$
$F_{\mathrm{w}} \quad$ Weight fraction of solid wax in the wax deposi- tion layer
$G \quad$ Mass flow of oil, $\mathrm{kg} / \mathrm{s}$
$G z_{\mathrm{h}} \quad$ The Graetz number in the energy transfer pro- cess
$G \mathrm{z}_{\mathrm{m}}$ The Graetz number in the mass transfer pro- cess,
$h_{\mathrm{i}} \quad$ Heat transfer coefficient, $\mathrm{W}\left(\mathrm{m}^{2}{ }^{\circ} \mathrm{C}\right)^{-1}$
$J_{\mathrm{c}} \quad$ Wax molecule pair flow of oil to the interface of the deposition layer, $\mathrm{kg} /\left(\mathrm{m}^{2} \mathrm{~s}\right)$
$J_{\mathrm{d}} \quad$ Diffusion flux of wax molecules that have dif- fused into the deposition layer, $\mathrm{kg} /\left(\mathrm{m}^{2} \mathrm{~s}\right)$
$J_{\mathrm{s}} \quad$ Shear flux of wax molecules in the deposition layer, $\mathrm{kg} /\left(\mathrm{m}^{2} \mathrm{~s}\right)$
* Corresponding author: wuming0413@sina.cn
$k_{\mathrm{m}}$
$k_{\mathrm{s}}$
$L$
$N_{\mathrm{u}}$
$P_{\mathrm{r}}$
$Q_{\mathrm{m}}$
Mass transfer coefficient, $\mathrm{m} / \mathrm{s}$
Shear coefficient
Length of the pipe, $m$
Nusselt number

\section{Prandtl number}
Annual mass flow rate of crude oil, $\mathrm{t} / \mathrm{a}$
Volume flow rate of crude oil, $\mathrm{m}^{3} / \mathrm{h}$
Average crystallization heat of the wax, $\mathrm{J} / \mathrm{g}$
Radius of the crude oil pipe, $m$
Effective radius for oil flow, $\mathrm{m}$
Radius of the pipe, $m$
Outer radius of the pipe, $\mathrm{m}$
Outer radius of the pipe with insulation, $\mathrm{m}$
The Reynolds number
Thermal resistance of wax layer per unit length, $\left(\mathrm{m}{ }^{\circ} \mathrm{C}\right) / \mathrm{W}$
$R_{\mathrm{T}, \text { ins }}$
Thermal resistance of pipe wall per unit length, $\left(\mathrm{m}{ }^{\circ} \mathrm{C}\right) / \mathrm{W}$
length, $\left(\mathrm{m}^{\circ} \mathrm{C}\right) / \mathrm{W}$
$S \quad$ Area enclosed by the thermal spectra curve and baseline, $\left(\mathrm{W}^{\circ} \mathrm{C}\right) / \mathrm{g}$
$S_{\mathrm{c}} \quad$ The Schmidt number 
Sh The Sherwood number in the process of mass transfer

T Absolute temperature of oil, ${ }^{\circ} \mathrm{C}$

$T_{0} \quad$ Temperature of oil in the center of the pipe, ${ }^{\circ} \mathrm{C}$

$T_{1} \quad$ Temperature of the outer wall of the pipe, ${ }^{\circ} \mathrm{C}$

$T_{2} \quad$ Temperature of the outer wall of the insulation layer, ${ }^{\circ} \mathrm{C}$

$T_{\mathrm{A}} \quad$ Ambient temperature, ${ }^{\circ} \mathrm{C}$

$T_{\mathrm{E}} \quad$ Temperature of the oil at the starting point of the pipe, ${ }^{\circ} \mathrm{C}$

$T_{\mathrm{i}} \quad$ Surface temperature of the wax deposition layer, ${ }^{\circ} \mathrm{C}$

$T_{\mathrm{w}} \quad$ Temperature of the inner wall of the pipe, ${ }^{\circ} \mathrm{C}$

$T_{\mathrm{Z}} \quad$ Temperature of the oil at a distance of $Z$ from the starting point of the pipe, ${ }^{\circ} \mathrm{C}$

$v \quad$ Cooling rate, ${ }^{\circ} \mathrm{C} / \mathrm{s}$

$V \quad$ Molar volume of the wax, $\mathrm{cm}^{3} / \mathrm{mol}$

$x \quad$ Axial position of the pipe, $\mathrm{m}$

\section{Greek letters}

$\begin{array}{ll}\alpha & \text { Wax crystal shape factor } \\ \delta & \text { Dimensional thickness of wax deposition layer } \\ \lambda_{0} & \text { Thermal conductivity of oil, } \mathrm{W}\left(\mathrm{m}^{\circ} \mathrm{C}\right)^{-1} \\ \lambda_{\mathrm{w}} & \text { Thermal conductivity of wax, } \mathrm{W}\left(\mathrm{m}{ }^{\circ} \mathrm{C}\right)^{-1} \\ \lambda_{\text {ins }} & \text { Thermal conductivity of the insulation layer, } \\ & \mathrm{W}\left(\mathrm{m}{ }^{\circ} \mathrm{C}\right)^{-1} \\ \lambda_{\text {steel }} & \text { Thermal conductivity of the pipe wall, W } \\ & \left(\mathrm{m}{ }^{\circ} \mathrm{C}\right)^{-1} \\ \lambda_{\text {total }} & \text { Total heat transfer coefficient, } \mathrm{W}\left(\mathrm{m}{ }^{\circ} \mathrm{C}\right)^{-1} \\ \delta_{\mathrm{w}} & \text { Thickness of the wax deposition layer, } \mathrm{m} \\ \mu & \text { Solvent viscosity, mPa s } \\ \rho_{\text {gel }} & \text { Density of wax deposition layer, } \mathrm{kg} / \mathrm{m}^{3}\end{array}$

\section{Introduction}

Pipeline transportation is a common method for longdistance blending of crude oil. The safety operation during the transportation process and reducing energy loss is a frequently mentioned topic in current research $[1,2]$. In the process of waxy crude oil pipeline transportation, the formation of wax deposition could reduce the effective conveying area of the pipeline, which decreases the conveying capacity of pipeline, enhances the energy consumption, and even causes huge safety hazards and economic losses by blocking pipeline [3]. Therefore, it is of great significant to predict the wax deposition rate, thickness and wax content of deposition during the transportation process of waxy crude oil through pipelines for the purpose of formulating wax removal plan [4].

Researchers have conducted a lot of study on wax deposition of oil pipelines. It has been acknowledged that molecular diffusion, shear dispersion, gravity settlement and Brownian diffusion are three main mechanisms governing the wax deposition process [5-7]. Hamouda and Viken (1993), and Brown and Niesen (1993) believed that the effect of shear dispersion on the wax deposition process is not significant $[8,9]$. In addition, the effect of Brownian diffusion on wax deposition is negligible [10]. Singh et al. considered the influence of aging on wax deposition on the basis of molecular diffusion and constructed a wax deposition prediction model for waxy crude oil pipeline [11]. Hernandez et al. improved it on the basis of the model built by Singh et al., taking into account the effects of molecular diffusion, shear stripping and aging and improved the prediction accuracy of the calculation model [12]. Zheng et al. developed an enhanced wax deposition model considering the non-Newtonian characteristics of waxy oil using the law of the wall method [13]. However, the current studies mentioned above were all conducted on the non-thermal pipeline which temperature field is very different from that on heat insulated pipeline. There have been few reports on the study of wax deposition behaviors for heat insulated pipeline transporting waxy crude oil.

In the present study, an indoor heat insulated loop experimental apparatus was established considering the actual situation of a new heat insulated pipeline in Northeast China which transports waxy crude oil. The wax deposition behaviors and the influence factors of wax deposition for various experimental conditions were investigated. A theoretical calculated model of wax thickness and wax content in heat insulated pipeline was established based on the principle of molecular diffusion, aging and shear effects. The results of the loop experiment and the model calculation results were compared and analyzed. The wax deposition thickness for the on-site pipeline was predicted for different seasons and operation time.

\section{Experiment study}

\subsection{Experimental apparatus}

Figure 1 is a schematic view of the indoor heat insulated loop experimental apparatus. The apparatus includes storage tank, circulation tank, pumps, pipelines, mechanical agitation system, water bath system, and Heat and Temperature Control Systems (HTCS). The circulation tank is used to store and heat crude oil at an operating pressure of 1.5 MPa. The pipelines include a reference section and a test section, both of which have the same casting material and the outer walls covered with heat insulation layers. The heat insulation layers are wrapped by water jackets on the outside. The water baths provide the water jackets constant temperature water to simulate the actual ambient temperature. The sizes of the pipes are $\Phi 48 \times 4 \mathrm{~mm}$ while the length is $1.2 \mathrm{~m}$, and the flow in the pipes could be controlled within the range from 0 to $100 \mathrm{dm}^{3} / \mathrm{min}$.

\subsection{Experimental procedure}

The waxy crude oil was collected from the oil transportation station and injected into the storage tank (Fig. 1). The crude oil was heated to a higher temperature 


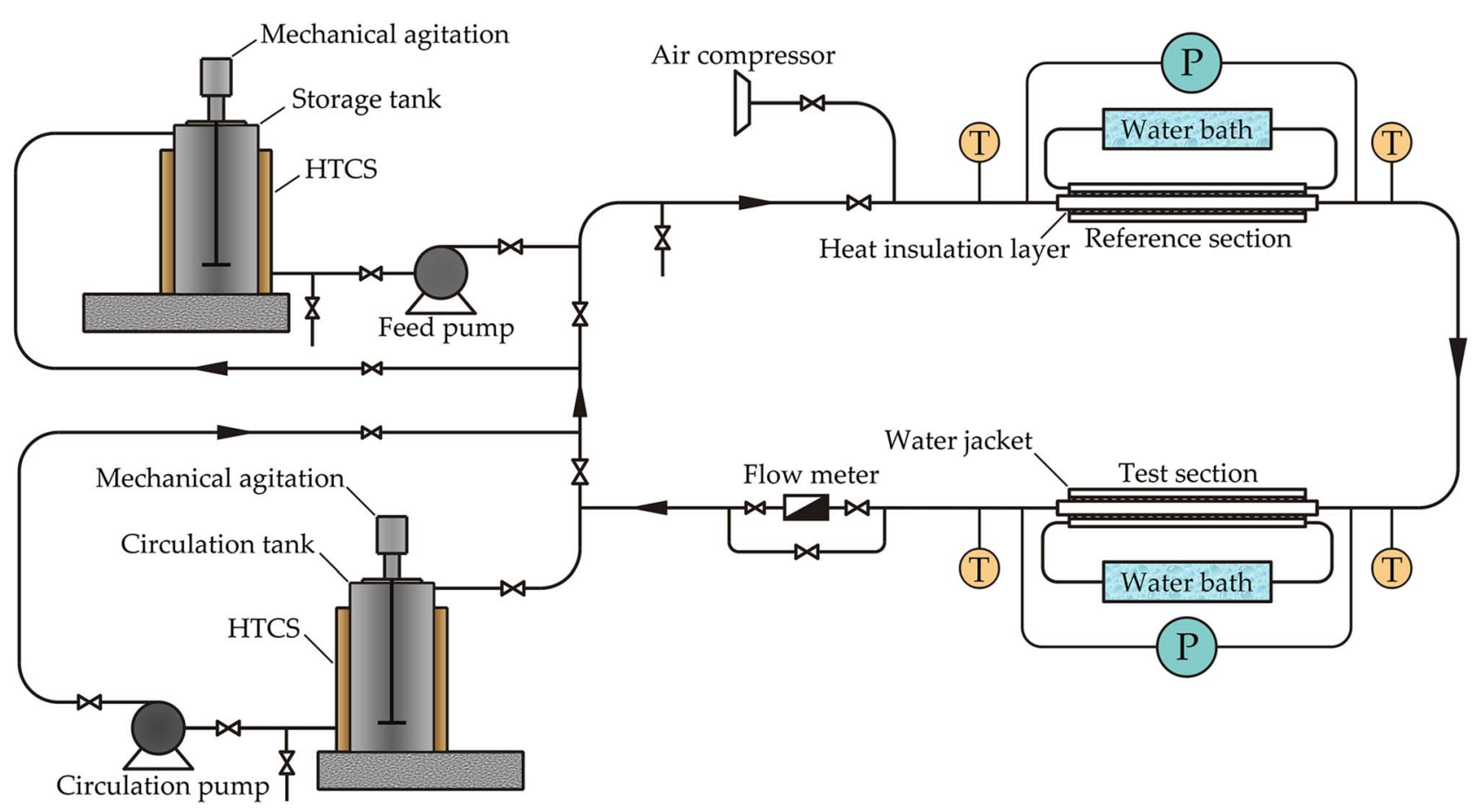

Fig. 1. The indoor heat insulated loop experimental apparatus.

(e.g., $50{ }^{\circ} \mathrm{C}$ ) and stirred to be flowable before the experiment started. Meanwhile, the temperatures of the two water baths were adjusted to the target values. The temperature of water bath on reference section was higher than the wax precipitation point of crude oil for the purpose of that no wax was deposited on the reference pipe wall. Conversely, the temperature of water bath on test section was lower than the wax precipitation point of crude oil to ensure wax could precipitate on the test pipe wall. After that, the feed pump was started and the oil was feed into the whole pipe system. Then the storage tank and feed pump were turned off, and the circulation tank and pump were used to keep oil flowing in the pipe during the experiment. By controlling water temperature, the test pipe wall was coated with wax in the inner surface but the reference pipe was not. The effective circulation area in test pipe decreased and the frictional resistance increased, which induced that the pressure drop on test section was higher than that on the reference section. The wax deposition thickness on test section could be inversely calculated through hydrodynamic calculation, i.e., differential pressure method. This method can be performed online without interrupting the experiment and it is the method available that can record the development of the wax thickness over time [14].

After the experiment, the oil was collected to the storage tank by air compressor. The test section was taken off carefully and the wax fraction in deposition layer was measured by Differential Scanning Calorimetry (DSC). The 5 10 mg gel sample was collected from the depositon layer at various sites. Before measurements, the DSC apparatus (Mettler Toledo DSC) was calibrated with ultra-pure indium. The temperature was set at $80^{\circ} \mathrm{C}$ and keeped at this temperature for $3 \mathrm{~min}$ to melt the sample evenly. After that, the gel was cooled with a rate of $5{ }^{\circ} \mathrm{C} / \mathrm{min}$ [15]. The typical thermal spectra curve of the oil used in this study was shown in Figure 2. The heat flow increased from the Wax Appearance Temperature (WAT), which is $43.38^{\circ} \mathrm{C}$ for the oil used in this study. The first wax precipitation peak occurred at $40.67{ }^{\circ} \mathrm{C}$ and the second one at $19.63{ }^{\circ} \mathrm{C}$. The area $(S)$ enclosed by the thermal spectra curve and baseline from $-20^{\circ} \mathrm{C}$ to WAT was calculated by integral. The average crystallization heat of the wax $\left(Q^{\prime}\right)$ for the present study is about $200 \mathrm{~J} / \mathrm{g}$. The wax fraction in gel was calculated by $F_{\mathrm{w}}=S /\left(v Q^{\prime}\right)$, in which $v$ is the cooling rate, ${ }^{\circ} \mathrm{C} / \mathrm{s}$.

\section{Development of the theoretical calculation model}

\subsection{Mass balance}

There is a radial temperature gradient inside the oil pipeline because of the temperature difference between oil and environment. The local solubility of the wax molecule in the oil flow is closely related to the in-site oil temperature. According to the molecular diffusion theory, wax crystals will precipitate from the crude oil and cause a radial wax concentration gradient in the pipe when the temperature of the pipe wall is lower than the WAT. The radial wax concentration gradient could accelerate wax deposition to pipe wall. The mass balance relationship of the process is shown in equation (1)

$$
\begin{aligned}
& \frac{\mathrm{d}}{\mathrm{d} t}\left[\pi\left(R^{2}-r_{\mathrm{i}}^{2}\right) F_{\mathrm{w}}(t) L \rho_{\text {gel }}\right] \\
& \quad=2 \pi r_{\mathrm{i}} L k_{\mathrm{m}}\left[C_{\mathrm{wb}}-C_{\mathrm{ws}}\left(T_{\mathrm{i}}\right)\right],
\end{aligned}
$$




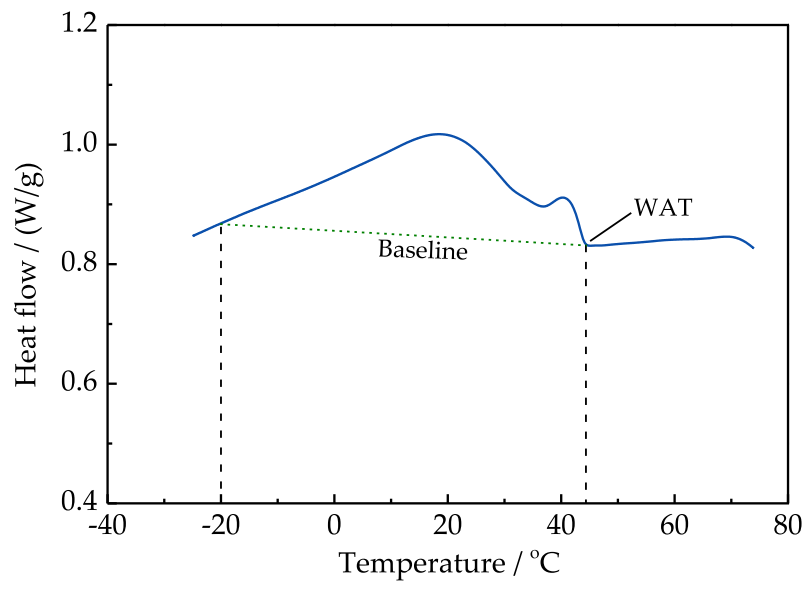

Fig. 2. Thermal spectra curve of the oil sample during cooling.

where $R$ is the radius of the pipe, $r_{\mathrm{i}}$ is the effective radius for oil flow, $F_{\mathrm{w}}$ is the weight fraction of solid wax in the wax deposition layer, $L$ is the length of the pipe, $\rho_{\text {gel }}$ is the density of wax deposition layer, $k_{\mathrm{m}}$ is the mass transfer coefficient, $C_{\mathrm{wb}}$ is the wax molecular concentration in oil, $C_{\mathrm{ws}}$ is the solubility of wax molecules in oil which is a function of the surface temperature of the wax deposition layer $T_{\mathrm{i}}$. In equation (1), $r_{\mathrm{i}}$ and $F_{\mathrm{w}}$ are both the function of operation time $t$. Assuming that the wax and the crude oil have the same density, equation (1) can be converted into

$$
\begin{gathered}
\pi\left(R^{2}-r_{\mathrm{i}}^{2}\right) \frac{\mathrm{d} F_{\mathrm{w}}(t)}{\mathrm{d} t}-2 \pi r_{\mathrm{i}} F_{\mathrm{w}}(t) \frac{\mathrm{d} r_{\mathrm{i}}}{\mathrm{d} t} \\
=\frac{2 \pi r_{\mathrm{i}} k_{\mathrm{m}}\left[C_{\mathrm{wb}}-C_{\mathrm{ws}}\left(T_{\mathrm{i}}\right)\right]}{\rho_{\text {gel }}} .
\end{gathered}
$$

To facilitate the calculation, the dimensionless thickness of wax deposition layer is set to be $\delta=\left(R-r_{\mathrm{i}}\right) / R$, then equation (2) is reduced to

$$
\frac{\delta(2-\delta)}{2(1-\delta)} \cdot \frac{\mathrm{d} F_{\mathrm{w}}(t)}{\mathrm{d} t}+F_{w}(t) \frac{\mathrm{d} \delta}{\mathrm{d} t}=\frac{k_{\mathrm{m}}\left[C_{\mathrm{wb}}-C_{\mathrm{ws}}\left(T_{\mathrm{i}}\right)\right]}{R \rho_{\mathrm{gel}}} .
$$

The mass transfer coefficient $k_{\mathrm{m}}$ in equation (3) is calculated according to

$$
k_{\mathrm{m}}=\frac{\mathrm{Sh} \cdot D_{\mathrm{wo}}}{2 R},
$$

where Sh is the Sherwood number in the mass transfer process, $D_{\text {wo }}$ is the wax molecular diffusivity in oil. The Hayduk-Minhas empirical formula was optimized using SPSS software to obtain a suitable formula for calculating the wax molecules diffusivity in mixing waxy crude oil [16], as shown in equation (5)

$$
D_{\text {wo }}=\frac{22.9 \times 10^{-13} \times T^{2.671} \mu^{\frac{10.2}{V}-1.351}}{V^{0.71}},
$$

where $T$ is the absolute temperature of oil, $\mu$ is the dynamic viscosity of oil, and $V$ is the molar volume of wax.
The value of Sh could be calculated depending on the flow pattern of the oil in pipeline. When the crude oil in the pipeline is laminar, it can be calculated using the Hausen correlation if the distance is long [17] and the Sieder and Tate correlation if the distance is short [18], as shown in equation (6):

$$
\mathrm{Gz}_{\mathrm{m}}<100, \quad \mathrm{Sh}=3.36+1.7813 \times 10^{-3} \times \frac{\mathrm{Gz}_{\mathrm{m}}^{5 / 3}}{\left(1+0.04 \times \mathrm{Gz}_{\mathrm{m}}^{2 / 3}\right)^{2}},
$$

$$
\mathrm{Gz}_{\mathrm{m}}>100, \quad \mathrm{Sh}=1.24 \times \mathrm{Gz}_{\mathrm{m}}^{1 / 3},
$$

where $\mathrm{Gz}_{\mathrm{m}}$ is the Graetz number in the mass transfer process, which can be calculated by using equation (7) [19]

$$
\mathrm{Gz}_{\mathrm{m}}=\frac{\mathrm{Re} \cdot \mathrm{Sc} \cdot 2 R}{x},
$$

where Re is the Reynolds number and calculated by $\operatorname{Re}=2 Q \rho / \pi r_{\mathrm{i}} \mu, x$ is the axial position of the pipe, $\mathrm{Sc}$ is the Schmidt number and can be calculated by $\mathrm{Sc}=\mu$ / $\rho D_{\text {wo }}$ [11]. When the crude oil is in a fully developed turbulent state, the local Sherwood number in the pipe could be calculated by the Dittus-Boelter Equation [20]:

$$
\mathrm{Sh}=0.023 \times \mathrm{Re}^{0.8} \mathrm{Sc}^{0.4} .
$$

The wax molecular solubility at the wax deposition layer changes with the oil temperature, and the wax molecular solubility curve of the crude oil obtained by the experiment is shown in equation (9)

$$
\begin{aligned}
C_{\mathrm{ws}}\left(T_{\mathrm{i}}\right)= & -0.0017 T_{\mathrm{i}}^{3}+0.0775 T_{\mathrm{i}}^{2}+3.8893 T_{\mathrm{i}} \\
& +70.765 .
\end{aligned}
$$

The differentiation of wax molecular solubility to temperature can be expressed as

$$
\frac{\mathrm{d} C_{\mathrm{ws}}\left(T_{\mathrm{i}}\right)}{\mathrm{d} T}=-0.0051 T_{i}^{2}+0.155 T_{i}+3.8893 .
$$

Due to the temperature gradient between the surface of the wax deposition layer and the inner wall of the tube, a concentration gradient of wax molecules exists inside the wax deposition layer. Therefore, there is also a diffusion flux of wax molecules inside the wax deposition layer, inducing the wax content inside the deposition layer gradually increased. According to mass balance, the formation process of the wax deposition layer can be expressed as

$$
\begin{aligned}
-2 \pi r_{\mathrm{i}} F_{\mathrm{w}}(t) \rho_{\text {gel }} \frac{\mathrm{d} r_{\mathrm{i}}}{\mathrm{d} t}= & 2 \pi r_{\mathrm{i}} k_{\mathrm{m}}\left[C_{\mathrm{wb}}-C_{\mathrm{ws}}\left(T_{\mathrm{i}}\right)\right] \\
& -2 \pi r_{\mathrm{i}}\left(-\left.D_{\mathrm{e}} \frac{\mathrm{d} C_{\mathrm{ws}}}{\mathrm{d} r}\right|_{\mathrm{i}}\right) .
\end{aligned}
$$

Equation (11) can be simplified to 


$$
F_{\mathrm{w}}(t) \frac{\mathrm{d} \delta}{\mathrm{d} t}=\frac{k_{\mathrm{m}}\left[C_{\mathrm{wb}}-C_{\mathrm{ws}}\left(T_{\mathrm{i}}\right)\right]}{R \rho_{\text {gel }}}+\left.\frac{D_{\mathrm{e}}}{R \rho_{\text {gel }}} \cdot \frac{\mathrm{d} C_{\mathrm{ws}}}{\mathrm{d} T} \cdot \frac{\mathrm{d} T}{\mathrm{~d} r}\right|_{\mathrm{i}},
$$

where $D_{\mathrm{e}}$ is the effective diffusivity of wax inside the deposition layer which could be calculated by the Cussler correlation [21]:

$$
D_{\mathrm{e}}=\frac{D_{\text {wo }}}{1+\alpha \cdot \frac{F_{\mathrm{w}}^{2}}{1-F_{\mathrm{w}}}},
$$

where $\alpha$ is the wax crystal shape factor which could be obtained by observing the wax crystal form of the deposition layer. The wax crystal morphology was processed and analyzed by Image J software and the relationship between $\alpha$ and the volume flow rate of crude oil $Q_{\mathrm{v}}$ was as following:

$$
\alpha=-0.323 \ln Q_{\mathrm{v}}+1.684 .
$$

Equations (3) and (12) were combined to obtain the wax content of the deposition layer as a function of time, as shown in equation (15).

$$
\frac{\mathrm{d} F_{\mathrm{w}}}{\mathrm{d} t}=-\left.\frac{D_{\mathrm{e}}}{R \rho_{\text {gel }}} \cdot \frac{\mathrm{d} C_{\mathrm{ws}}}{\mathrm{d} T} \cdot \frac{\mathrm{d} T}{\mathrm{~d} r}\right|_{\mathrm{i}} \cdot \frac{2(1-\delta)}{\delta(2-\delta)} .
$$

\subsection{Energy balance}

The schematic diagram of the thermal analysis on the indoor waxing test pipeline is shown in Figure 3. It is assumed that the whole test section is uniformly covered by wax, and the thickness of the wax deposition layer is $\delta_{\mathrm{w}}$.

The temperature of the outer wall of insulation layer $\left(T_{2}\right)$ is equal to the temperature of water bath for the indoor test pipeline or the soil temperature for the actual buried pipeline. The center temperature of oil $T_{0}$ is usually known. The heat flow balance relationship at each radius of the heat insulated crude oil pipeline can be obtained according to the theory of thermal resistance, as shown in equation (16).

$$
\begin{aligned}
2 \pi R(1-\delta) h_{\mathrm{i}}\left(T_{0}-T_{\mathrm{i}}\right) & =\frac{T_{\mathrm{i}}-T_{\mathrm{w}}}{\frac{1}{2 \pi \lambda_{\mathrm{w}}} \ln \frac{1}{1-\delta}}=\frac{T_{\mathrm{w}}-T_{1}}{\frac{1}{2 \pi \lambda_{\text {steel }}} \ln \frac{R_{1}}{R}} \\
& =\frac{T_{1}-T_{2}}{\frac{1}{2 \pi \lambda_{\text {ins }}} \ln \frac{R_{2}}{R_{1}}},
\end{aligned}
$$

where $h_{\mathrm{i}}$ is the heat transfer coefficient, $T_{0}$ is the center temperature of oil, $T_{\mathrm{w}}$ is the temperature of the inner wall of the pipe, $T_{1}$ is the temperature of the outer wall of the pipe, $\lambda_{\mathrm{w}}$ is the effective thermal conductivity of wax layer, $\lambda_{\text {steel }}$ is the thermal conductivity of the pipe wall, $\lambda_{\text {ins }}$ is the thermal conductivity of the insulation layer, $R_{1}$ is the outer radius of the pipe, and $R_{2}$ is the outer radius of insulation layer. In equation (16), three thermal resistances per unit length $\left(R_{\mathrm{T}}\right)$ can be defined as following:

$$
R_{\mathrm{T}, \mathrm{w}}=\frac{1}{2 \pi \lambda_{\mathrm{w}}} \ln \frac{1}{1-\delta},
$$

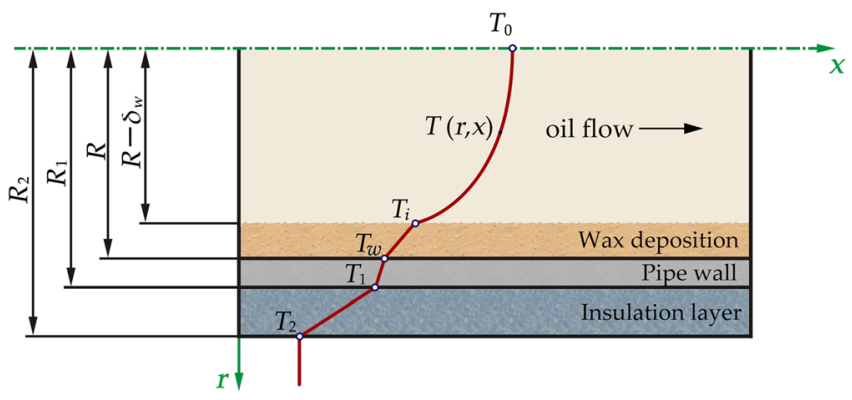

Fig. 3. Schematic diagram of thermal analysis of indoor waxing test pipeline.

$$
\begin{aligned}
R_{\mathrm{T}, \text { steel }} & =\frac{1}{2 \pi \lambda_{\text {steel }}} \ln \frac{R_{1}}{R}, \\
R_{\mathrm{T}, \text { ins }} & =\frac{1}{2 \pi \lambda_{\text {ins }}} \ln \frac{R_{2}}{R_{1}} .
\end{aligned}
$$

Equation (16) can be simplified to get the expressions of $T_{\mathrm{w}}$ and $T_{\mathrm{i}}$ as shown below.

$$
T_{\mathrm{i}}=\frac{T_{2}+2 \pi h_{\mathrm{i}} T_{0} R(1-\delta)\left(R_{\mathrm{T}, \mathrm{w}}+R_{\mathrm{T}, \text { steel }}+R_{\mathrm{T}, \text { ins }}\right)}{1+2 \pi h_{\mathrm{i}} R(1-\delta)\left(R_{\mathrm{T}, \mathrm{w}}+R_{\mathrm{T}, \text { steel }}+R_{\mathrm{T}, \text { ins }}\right)},
$$

$$
T_{\mathrm{w}}=T_{\mathrm{i}}-2 \pi R(1-\delta) h_{\mathrm{i}}\left(T_{0}-T_{\mathrm{i}}\right) R_{\mathrm{T}, \mathrm{w}} .
$$

The temperature gradient of the surface of the deposited layer can be obtained after further derivation.

$$
\left.\frac{\mathrm{d} T}{\mathrm{~d} r}\right|_{\mathrm{i}}=\frac{T_{\mathrm{i}}-T_{\mathrm{w}}}{R(1-\delta) \ln (1-\delta)} .
$$

The heat transfer coefficient $h_{\mathrm{i}}$ can be calculated by following equation [11]:

$$
h_{\mathrm{i}}=\frac{\mathrm{Nu} \times \lambda_{0}}{2 R},
$$

where $\mathrm{Nu}$ is the Nusselt number, which calculation method is similar to that of the Sherwood number mentioned above. When the oil in the pipeline is in laminar flow, it can be calculated using the Hausen correlation [17] and the Sieder and Tate correlations [18]:

$$
\mathrm{Gz}_{\mathrm{h}}<100, \quad \mathrm{Nu}=3.36+1.7813 \times 10^{-3} \times \frac{\mathrm{Gz}_{\mathrm{h}}^{5 / 3}}{\left(1+0.04 \times \mathrm{Gz}_{\mathrm{h}}^{2 / 3}\right)^{2}},
$$

$$
\mathrm{Gz}_{\mathrm{h}}>100, \quad \mathrm{Nu}=1.24 \times \mathrm{Gz}_{\mathrm{h}}^{1 / 3},
$$

where $\mathrm{Gz}_{\mathrm{h}}$ is the Graetz number in the energy transfer process, which can be calculated using equation (23). 


$$
\mathrm{Gz}_{\mathrm{h}}=\frac{\operatorname{Re} \cdot \operatorname{Pr} \cdot 2 R}{x},
$$

where $\operatorname{Pr}$ is the Prandtl number and the calculation method is as follow.

$$
\operatorname{Pr}=\frac{\mu c_{\mathrm{p}}}{\lambda_{0}}
$$

where $c_{\mathrm{p}}$ is the constant pressure specific heat capacity of crude oil, and $\lambda_{0}$ is the thermal conductivity of crude oil. When the oil in pipeline is in a fully developed turbulent state, the Nusselt number in the pipe could be calculated using the Colburn Equation [20]:

$$
\mathrm{Nu}=0.023 \operatorname{Re}^{0.8} \operatorname{Pr}^{1 / 3} .
$$

The effective thermal conductivity of the deposition layer $\lambda_{\mathrm{w}}$ can be calculated using the EMT model [22]:

$$
\lambda_{\mathrm{w}}=\frac{2 \lambda_{\mathrm{wax}}+\lambda_{\text {oil }}+\left(\lambda_{\mathrm{wax}}-\lambda_{\text {oil }}\right) F_{\mathrm{w}}}{2 \lambda_{\mathrm{wax}}+\lambda_{\mathrm{oil}}-2\left(\lambda_{\mathrm{wax}}-\lambda_{\text {oil }}\right) F_{\mathrm{w}}} \lambda_{\mathrm{oil}},
$$

where $\lambda_{\text {wax }}$ and $\lambda_{\text {oil }}$ is the thermal conductivity of wax and oil respectively.

For long distance pipeline, the temperature of crude oil at the axial position of different pipe sections can be calculated using the temperature drop formula [23]:

$$
T_{\mathrm{z}}=T_{\mathrm{e}}+\left(T_{\mathrm{s}}-T_{\mathrm{e}}\right) \exp \left(-\frac{2 \pi R_{2} \lambda_{\text {total }}}{G c_{p}} \cdot z\right),
$$

where $T_{\mathrm{z}}$ is the temperature of the oil at a distance of $z$ from the starting point of the pipe, $T_{\mathrm{S}}$ is the temperature of the oil at the starting point of the pipe, $T_{\mathrm{e}}$ is the environment temperature, $\lambda_{\text {total }}$ is the total heat transfer coefficient, and $G$ is the mass flow of oil. The total heat transfer coefficient for buried pipeline is calculated using by [24]:

$$
\frac{1}{\lambda_{\text {total }} D}=\frac{1}{h_{\mathrm{i}} D_{1}}+\sum \frac{1}{2 \lambda_{\mathrm{i}}} \ln \frac{D_{\mathrm{i}+1}}{D_{\mathrm{i}}}+\frac{1}{2 \alpha_{2} R_{2}},
$$

where $D$ is the calculated diameter, which is equal to take the average of the inner and outer diameters of the insulation layer for the insulated pipe, $D_{1}$ is the effective diameter of the pipe, $D_{\mathrm{i}}$ and $D_{\mathrm{i}+1}$ are the inner and outer diameters of the pipe and the insulation layer, $\lambda_{\mathrm{i}}$ is the corresponding thermal conductivity of the pipe and the insulation layer, $\alpha_{2}$ is the convective heat transfer coefficient of the outer wall of the insulation layer to the soil.

\subsection{Kinetic calculation model for wax deposition}

In the process of waxy crude oil transportation, wax deposition is caused by the interaction of molecular diffusion, aging and shearing. Due to the concentration gradient of wax molecules in the oil flow, the wax molecules continuously diffuse from the center of the higher concentration oil to the lower concentration wax deposition layer. Additionally, the shear stress generated during the transportation causes the wax molecules to peel off at the interface

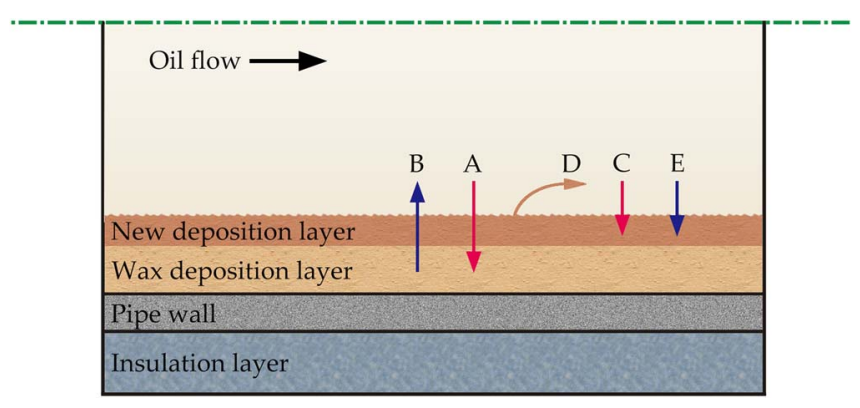

Fig. 4. Kinetic principle of wax deposition process.

of the wax deposition layer. In Section 3.1, only molecular diffusion and aging effect were taken account. Next, the shearing thinning will be added by flux analysis. The kinetic principle of this process is shown in Figure 4. The mass balance of the unidirectional flow wax deposition process can be described as follows taking into account these factors: the cumulative total weight of the wax deposition layer "T"; the mass of the wax diffused into the deposition layer "A"; the mass of the crude oil diffused out of the deposition layer "B"; the wax increment of the newly formed deposition layer "C"; the mass of the stripped wax caused by shearing "D"; the mass of the crude oil in the newly formed deposition "E".

This process is described using the mass balance equation shown below [12].

$$
T=A-B+C-D+E .
$$

$A$ and $B$ are of equal mass and therefore cancel each other out in equation (29). T, C, D and $E$ are described below.

$$
\begin{gathered}
T=\frac{\mathrm{d}}{\mathrm{d} t}\left[\pi\left(r^{2}-r_{\mathrm{i}}^{2}\right)\right] \rho L, \\
C=\left(J_{\mathrm{c}}-J_{\mathrm{d}}\right) \cdot 2 \pi r_{\mathrm{i}} L, \\
D=J_{\mathrm{s}} \cdot 2 \pi r_{\mathrm{i}} L, \\
E=\left(J_{\mathrm{c}}-J_{\mathrm{d}}-J_{\mathrm{s}}\right)\left(\frac{1-F_{\mathrm{w}}}{F_{\mathrm{w}}}\right) \cdot 2 \pi r_{\mathrm{i}} L .
\end{gathered}
$$

Among them, $J_{\mathrm{c}}$ represents the wax molecule pair flow of oil to the interface of the deposition layer, the expression is shown as

$$
J_{\mathrm{c}}=k_{\mathrm{m}}\left[C_{\mathrm{wb}}-C_{\mathrm{ws}}\left(T_{\mathrm{i}}\right)\right]
$$

$J_{\mathrm{d}}$ represents the diffusion flux of wax molecules that have diffused into the deposition layer, the expression is shown as

$$
J_{\mathrm{d}}=-\left.D_{\mathrm{e}} \frac{\mathrm{d} C_{w s}}{\mathrm{~d} r}\right|_{\mathrm{i}}
$$


$J_{\mathrm{s}}$ represents the shear flux of wax molecules in the deposition layer. Based on the principle of shear energy, the shear flux relationship describing the single-phase flow wax deposition process is established as shown in the following equation [25]:

$$
J_{\mathrm{s}}=k_{\mathrm{s}} \alpha\left|\frac{\mathrm{d} E_{\mathrm{s}}}{\mathrm{d} L}\right|_{r_{\mathrm{i}}} \frac{\rho_{\mathrm{w}} \mu F_{\mathrm{w}}^{1.3}}{r_{1}},
$$

where $k_{\mathrm{s}}$ is the shear coefficient, which can be determined by regression of laboratory data, $\left|\frac{\mathrm{d} E_{s}}{\mathrm{~d} L}\right|_{r}$ is the unit shear energy at a distance of $L$ from the initial position of the pipe when the distance from the center of the pipe flow to the surface of the sediment is different.

By replacing the $r_{\mathrm{i}}$ with $\delta$ and bringing equations (30a) (33) into equation (12), the wax deposition calculation model can be expressed as

$$
\frac{\mathrm{d} \delta}{\mathrm{d} t}=\frac{J_{\mathrm{c}}-J_{\mathrm{d}}-J_{\mathrm{s}}}{\rho F_{\mathrm{w}}} .
$$

\subsection{Solution of the calculation model}

In equations (15) and (34), there are total two unknown variables, i.e., $\delta$ and $F_{\mathrm{w}}$. The equation set is closed and theoretically solvable. However, it is a differential equation system and can not be solved directly. In this study, the Euler method was used to solve the equation set numerically.

The kinetic calculation model of wax deposition in waxy crude oil pipe was solved, and the variation of wax deposition thickness and wax content in the deposition layer with time was obtained. It is assumed that a very thin wax deposition has appeared at the wall of the initial stage, and the initial wax content in the deposition layer is the same as that in the crude oil. The pipe is divided into $N$ segments along the axial direction of the pipe, and the time is divided into $M$ segments. The wax deposition law at different positions and times in the pipe is analyzed. The block diagram of the wax deposition calculation model is shown in Figure 5 .

\section{Results and discussion}

The wax deposition thickness in the experimental pipe was obtained by solving the wax deposition calculation model proposed in this paper. The calculated values of the thickness and wax content of the wax deposition layer in the pipe varied with time were compared with the experimental data.

\subsection{Effect of flow on wax deposition}

Figure 6 shows the comparison of the experimental and calculation values of the deposition layer thickness and wax content at three different flows at a constant ambient temperature. The water bath temperature of the experimental loop was set at $28^{\circ} \mathrm{C}$. The flow rate in the section is 1.2, 1.5 and $1.8 \mathrm{~m}^{3} / \mathrm{h}$, respectively. $K_{\mathrm{s}}$ in equation (33) was conversely fitted by the regression of laboratory data, which

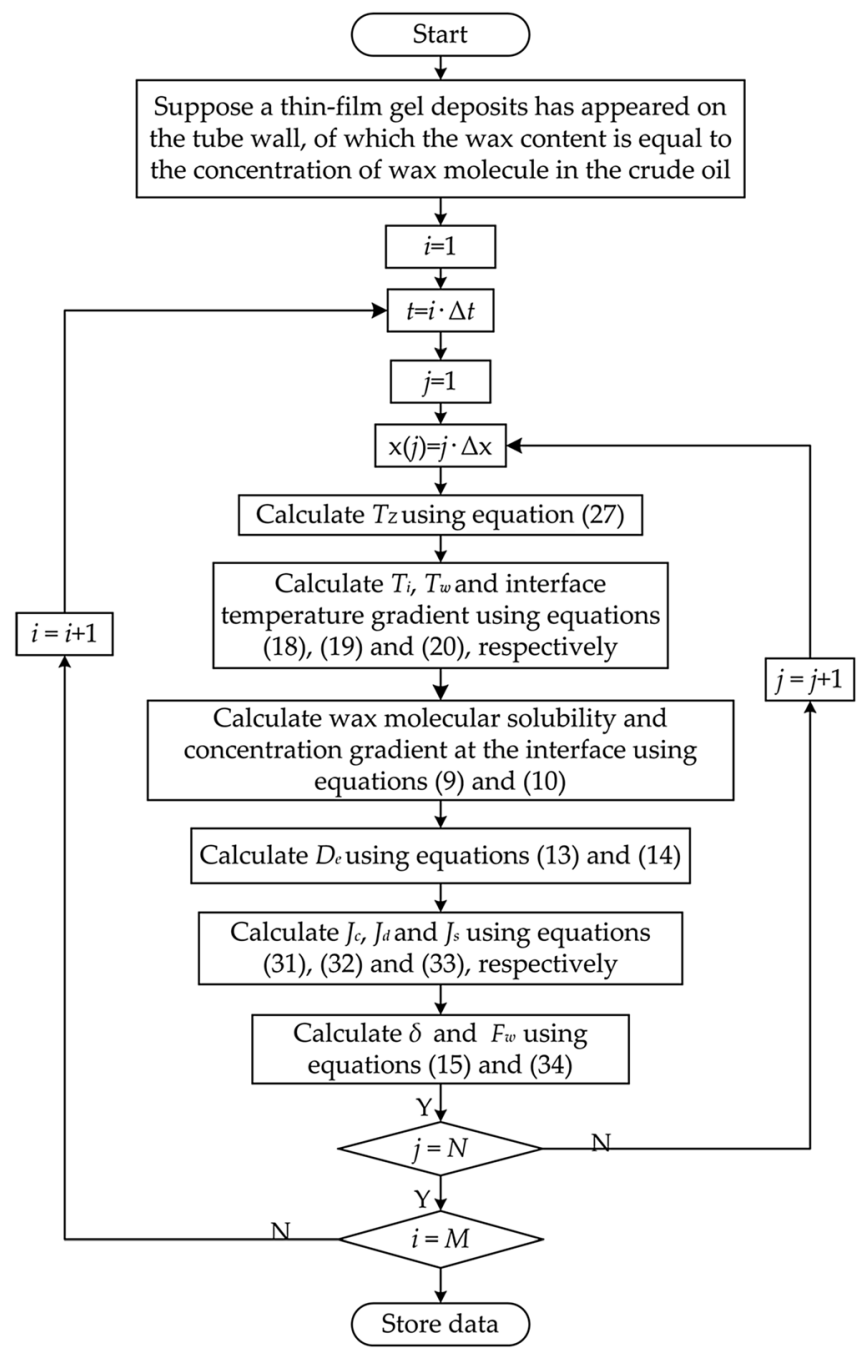

Fig. 5. The calculation block diagram for solving wax deposition prediction model.

is about $4.5 \times 10^{-12}$ for the oil and conditions in the study. The remaining parameters and oil properties are shown in Table 1. Figure 6 shows that the thicknesses of the wax deposition layer increase with the experimental time and finally stabilize at a specific value. This is mainly because of the enhanced shear thinning effect with velocity (inversely proportional to effective radius as flow rates is fixed), as shown in equation (33). In addition, the stable thickness decreases with the increase of the flow rate. The wax content increases with the experimental time and the flow rate at a specific time, indicating the aging existed in the wax deposition process. When the temperature of the water bath in the experimental loop is constant, the theoretical values at three different flow rates agree well with the experimental values.

\subsection{Effect of ambient temperature on wax deposition}

Figure 7 shows the comparison of experimental and calculated values of the thickness and wax content of wax deposition layer at different ambient temperatures. The 


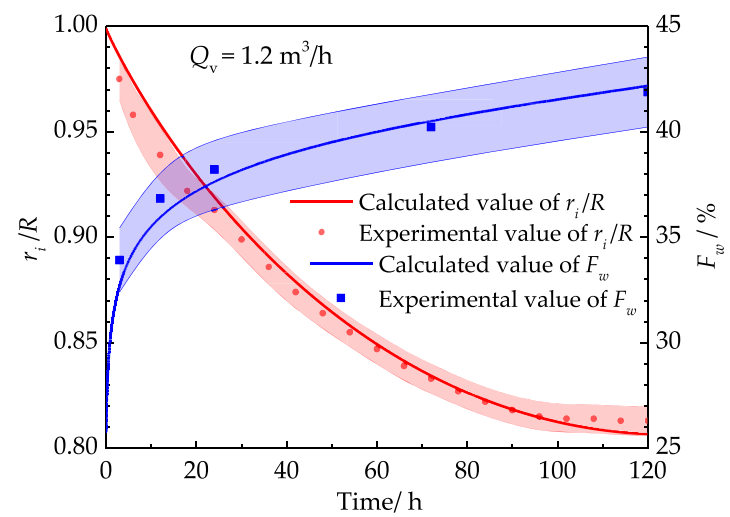

(a)

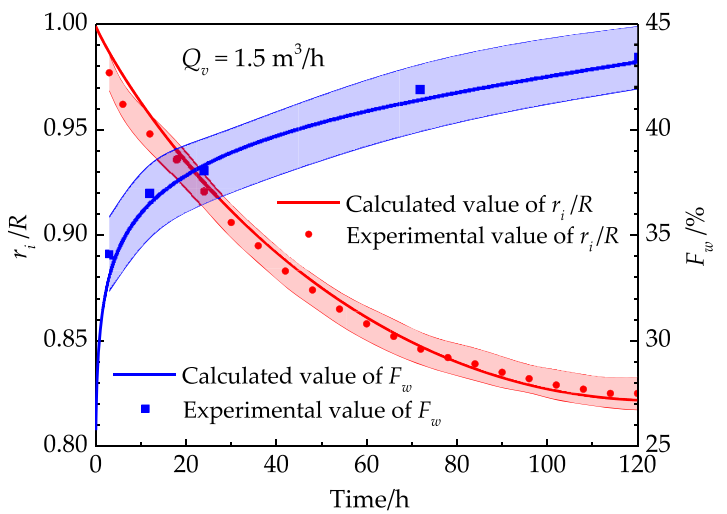

(b)

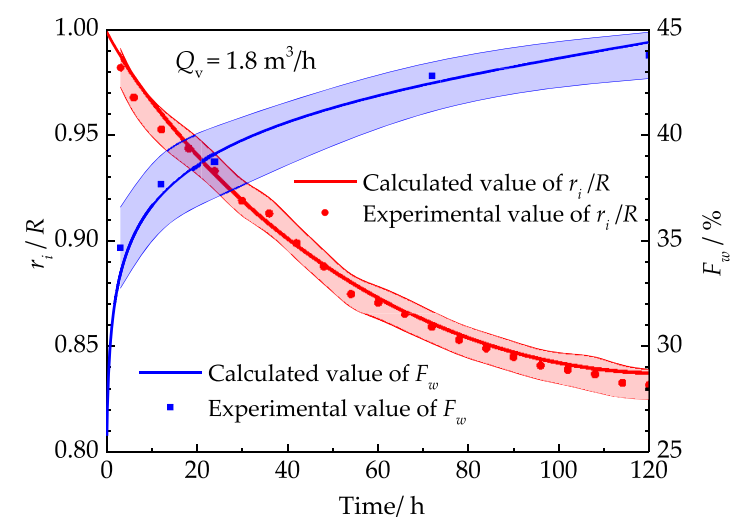

(c)

Fig. 6. Comparison of experimental and theoretical values for the wax deposition under different flow rates and bath temperature of $28{ }^{\circ} \mathrm{C}$ during the wax deposition: (a) $Q_{\mathrm{v}}=1.2 \mathrm{~m}^{3} / \mathrm{h}$, (b) $Q_{\mathrm{v}}=1.5 \mathrm{~m}^{3} / \mathrm{h}$ and (c) $Q_{\mathrm{v}}=1.8 \mathrm{~m}^{3} / \mathrm{h}$. Both of the averages and error bands were used to express the experiment results.

Table 1. Loop experiment scheme and related parameters.

\begin{tabular}{lccc}
\hline Parameters & Value & Parameters & Value \\
\hline$T_{0}\left({ }^{\circ} \mathrm{C}\right)$ & 40 & $\lambda_{\text {ins }}\left(\mathrm{W}\left[\mathrm{m}{ }^{\circ} \mathrm{C}\right]\right)^{-1}$ & 0.047 \\
WAT $\left({ }^{\circ} \mathrm{C}\right)$ & 44.38 & $\lambda_{0}\left(\mathrm{~W}\left[\mathrm{~m}{ }^{\circ} \mathrm{C}\right]\right)^{-1}$ & 0.14 \\
$R(\mathrm{~m})$ & 0.02 & $\lambda_{\mathrm{w}}\left(\mathrm{W}\left[\mathrm{m}{ }^{\circ} \mathrm{C}\right]\right)^{-1}$ & 0.25 \\
$R_{1}(\mathrm{~m})$ & 0.024 & $\lambda_{\text {steel }}\left(\mathrm{W}\left[\mathrm{m}{ }^{\circ} \mathrm{C}\right]\right)^{-1}$ & 54 \\
$R_{2}(\mathrm{~m})$ & 0.029 & $\rho_{\text {oil }}\left(\mathrm{kg} \mathrm{m}^{-3}\right)$ & 850 \\
$L(\mathrm{~m})$ & 1.2 & $c_{\mathrm{p}}\left(\mathrm{J}\left[\mathrm{kg}^{\circ} \mathrm{C}\right]\right)^{-1}$ & 2250 \\
\hline
\end{tabular}

experimental loop flow rate $Q_{\mathrm{v}}$ was set to $1.5 \mathrm{~m}^{3} / \mathrm{h}$. The water bath temperature of experimental loop $T_{2}$ was kept at 24,28 and $32^{\circ} \mathrm{C}$, respectively. The related parameters and oil physical properties are shown in Table 1. As shown in Figure 7, the thickness of the wax deposition layer decreases with the increase of the water bath temperature. It was attributed to the lower bath temperature induces a lower pipe wall temperature and facilitates the wax crystal diffusing toward the pipe wall.

The wax content increases with the ambient temperature at the same experiment duration. When the flow rate in the pipe is constant, the higher the ambient temperature is, the smaller the thickness of the deposit layer is. The thinner deposit layer increases the temperature gradient in the deposit layer, which increases the diffusion flux in the deposit layer, leads to the continuous diffusion of wax molecules into the deposit layer, and increases the wax content in the deposit layer.

\subsection{Prediction of wax deposition thickness for the on-site pipeline}

In this study, the crude oil heat insulated pipeline in Northeast China was selected as the research object. The calculation model proposed above was used to predict the wax deposition thickness of this pipeline. The operating parameters and oil physical properties are shown in Table 2. The wax deposition thickness distribution along the pipe varied with time in winter and summer is predicted respectively, as shown in Figure 8.

The prediction results show that the wax deposition thickness in the crude oil heat insulated pipeline tends to increase first and then decrease along the pipe either in winter or in summer. This phenomenon was also observed in practice. The maximum of the wax deposition thickness appears at $6 \mathrm{~km}$ in the axial direction in winter and at 


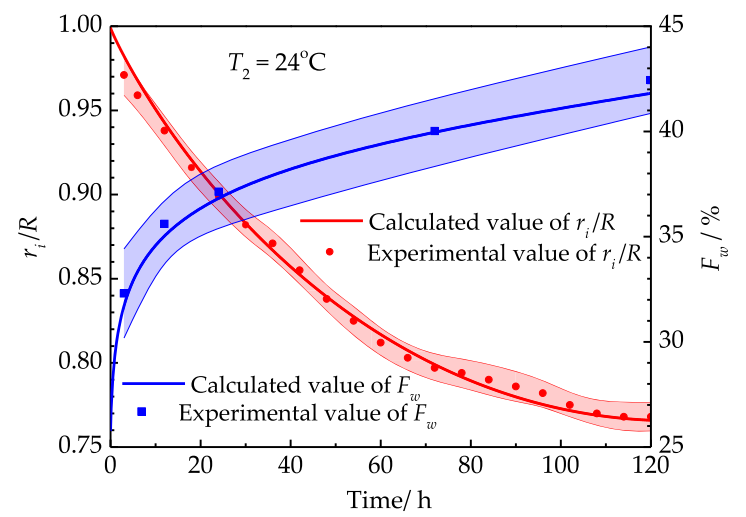

(a)

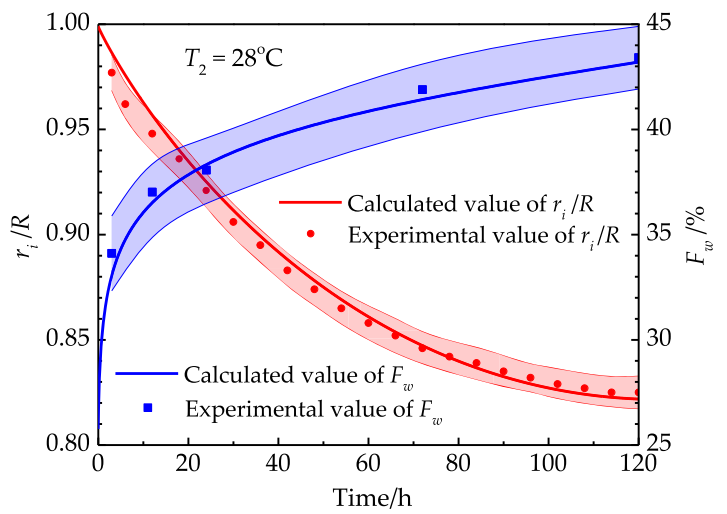

(b)

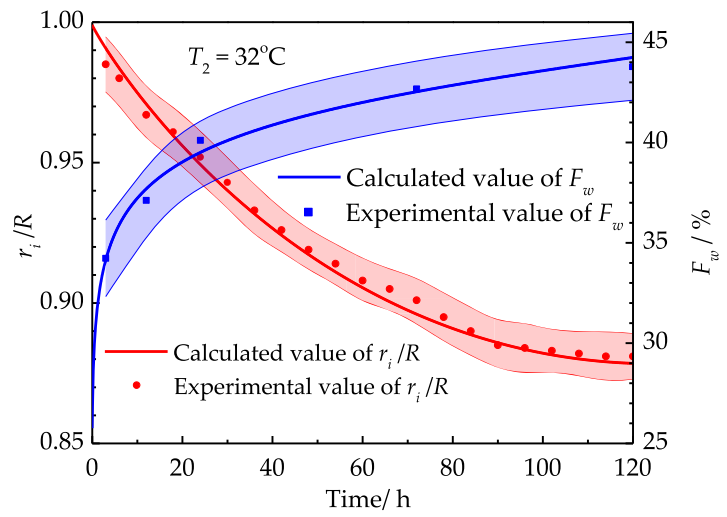

(c)

Fig. 7. Comparison of experimental and theoretical values for the wax deposition under different water bath temperature and flow rate of $1.5 \mathrm{~m}^{3} / \mathrm{h}$ during the wax deposition: (a) $T_{2}=24{ }^{\circ} \mathrm{C}$, (b) $T_{2}=28{ }^{\circ} \mathrm{C}$ and (c) $T_{2}=32{ }^{\circ} \mathrm{C}$.

Table 2. Operating parameters and crude oil property parameters of the insulated crude oil pipeline in section.

\begin{tabular}{lccc}
\hline Parameters & Value & Parameters & Value \\
\hline$R(\mathrm{~mm})$ & 355.6 & $\lambda_{\text {steel }}\left(\mathrm{W}\left[\mathrm{m}{ }^{\circ} \mathrm{C}\right]\right)^{-1}$ & 54 \\
$R_{1}(\mathrm{~mm})$ & 361.9 & $\rho_{\text {oil }}\left(\mathrm{kg} \mathrm{m}^{-3}\right)$ & 850 \\
$R_{2}(\mathrm{~mm})$ & 411.9 & $T_{0}$ in winter $\left({ }^{\circ} \mathrm{C}\right)$ & 40.3 \\
$L(\mathrm{~km})$ & 57.2 & $T_{0}$ in summer $\left({ }^{\circ} \mathrm{C}\right)$ & 40.2 \\
$Q_{\mathrm{m}}\left(\mathrm{t} \mathrm{a}{ }^{-1}\right)$ & $350 \times 10^{4}$ & $T_{\mathrm{A}}$ in winter $\left({ }^{\circ} \mathrm{C}\right)$ & 3 \\
$\lambda_{\text {ins }}\left(\mathrm{W}\left[\mathrm{m}^{\circ} \mathrm{C}\right]\right)^{-1}$ & 0.047 & $T_{\mathrm{A}}$ in summer $\left({ }^{\circ} \mathrm{C}\right)$ & 15 \\
$\lambda_{0}\left(\mathrm{~W}\left[\mathrm{~m}^{\circ} \mathrm{C}\right]\right)^{-1}$ & 0.14 & WAT $\left({ }^{\circ} \mathrm{C}\right)$ & 44.38 \\
$\lambda_{\mathrm{w}}\left(\mathrm{W}\left[\mathrm{m}^{\circ} \mathrm{C}\right]\right)^{-1}$ & 0.25 & & \\
\hline
\end{tabular}

$7.5 \mathrm{~km}$ in summer. The process of waxing in winter was taken as a research object to analyze the phenomenon. The oil temperature drops rapidly from the starting point of the pipe to the position of $6 \mathrm{~km}$. There is a large temperature gradient between the center position of the pipe and the interface of the deposition layer considering the low temperature of the wall, resulting in the diffusion of wax molecules. This is considered as the reason that the wax deposition thickness grows rapidly in the front section of the pipe. After a turning distance (i.e., $6 \mathrm{~km}$ for winter), the temperature at the center of the oil drops to a lower temperature, which causes the temperature gradient between the center of oil and the deposition layer to decreases and the deposition driving force of the wax molecules decreases. This results in a gradual decrease in the thickness of the wax deposition layer. The thickness of the wax deposition layer in the pipeline in winter is greater than that in summer. This is because the ambient temperature in winter is lower than that in summer, resulting in a larger temperature gradient between the center of the oil and the wall of the pipe, which accelerates the deposition rate of wax molecules. 


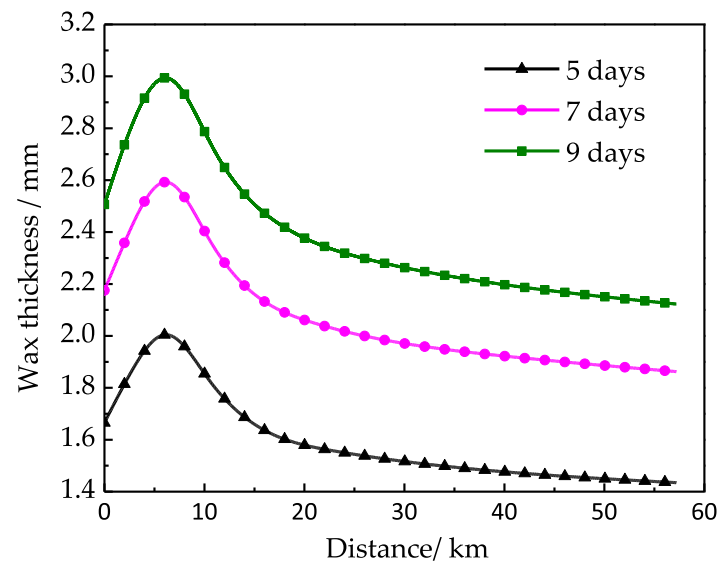

(a)

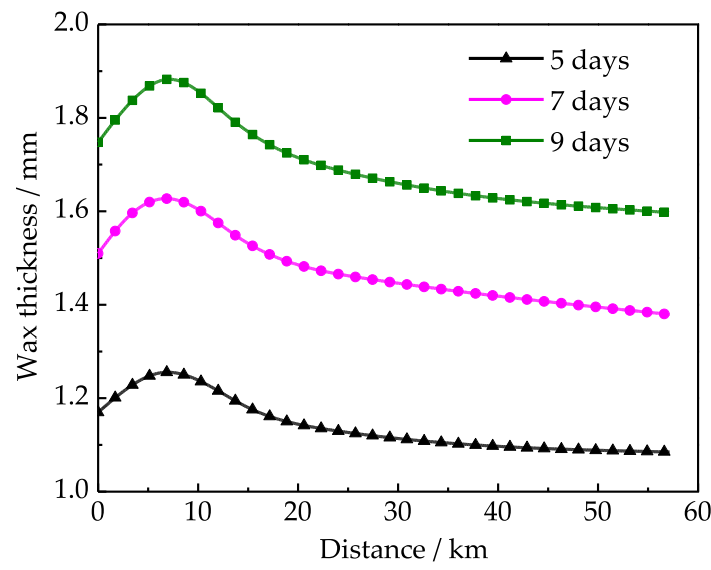

(b)

Fig. 8. Prediction results of wax deposition thickness distribution along insulated pipes in different seasons: (a) winter and (b) summer.

\section{Conclusion}

1. In view of the wax deposition condition of the waxy crude oil heat insulated pipeline, an experimental apparatus for the wax deposition loop of the crude oil heat insulated pipeline was established based on the differential pressure measurement principle. A theoretical kinetic calculation model of wax deposition for crude oil heat insulated pipeline was established considering the influence of molecular diffusion, aging and shearing on the wax deposition process.

2. The effects of flow rate and ambient temperature on the wax deposition process were studied both by experimental and theoretical method. The experimental results show that the wax deposition thickness decreases and the wax content increases with the flow rate increasing. The wax deposition thickness decreases and the wax content increases with the ambient temperature increasing. The calculated results of the model are in good agreement with the experimental values.

3. The wax deposition kinetic calculation model was used to predict the wax deposition law of the on-site heat insulated pipe in different seasons. The results showed that the thickness of the wax deposition layer increases first and then decreases along the pipeline.

\section{Conflicts of interest}

The authors declare no financial conflicts of interest regarding the publication of this paper.

Acknowledgments. This research was funded by the National Energy Administration of China, grant numbers 2017010000 and 2015010003.

\section{References}

1 Li C.X., Zhu H.R., Yang F., Liu H.Y., Wang F., Sun G.Y., Yao B. (2019) Effect of asphaltene polarity on wax precipitation and deposition characteristics of waxy oils, Energy Fuels 33, 8, 7225-7233.

2 Cheng Q.L., Gan Y.F., Su W.K., Liu Y., Sun W., Xu Y. (2017) Research on exergy flow composition and exergy loss mechanisms for waxy crude oil pipeline transport processes, Energies 10, 12, 20.

3 Wang J., Zhou F.J., Zhang L.T., Huang Y.X., Yao E.D., Zhang L., Wang F., Fan F. (2019) Experimental study of wax deposition pattern concerning deep condensate gas in Bozi block of Tarim Oilfield and its application, Thermochim. Acta 671, 1-9.

4 Zhu H.R., Li C.X., Yang F., Liu H.Y., Liu D.H., Sun G.Y., Yao B., Liu G., Zhao Y.S. (2018) Effect of thermal treatment temperature on the flowability and wax deposition characteristics of changqing waxy crude oil, Energy Fuels 32, 10, 10605-10615.

5 El-Dalatony M.M., Jeon B.H., Salama E., Eraky M., Kim W.B., Wang J., Ahn T. (2019) Occurrence and characterization of paraffin wax formed in developing wells and pipelines, Energies 12, 6, 23.

6 Van der Geest C., Guersoni V.C.B., Merino-Garcia D., Bannwart A.C. (2018) Wax deposition experiment with highly paraffinic crude oil in laminar single-phase flow unpredictable by molecular diffusion mechanism, Energy Fuels 32, 3, 3406-3419.

7 Chi Y.D., Daraboina N., Sarica C. (2017) Effect of the flow field on the wax deposition and performance of wax inhibitors: Cold finger and flow loop testing, Energy Fuels 31, 5, 4915-4924.

8 Hamouda A.A., Viken B.K. (1993) Wax deposition mechanism under high-pressure and in presence of light hydrocarbons, SPE International Symposium on Oilfield Chemistry, 2-5 March, New Orleans, Louisiana, USA.

9 Brown T., Niesen V. (1993) Measurement and prediction of the kinetics of paraffin deposition, SPE Annual Technical 
Conference and Exhibition, 3-6 October, Houston, Texas, $U S A$.

10 Burger E.D., Perkins T.K., Striegler J.H. (1981) Studies of wax deposition in the trans alaska pipeline, J. Pet. Technol. 33, 6, 1075-1086.

11 Singh P., Venkatesan R., Fogler H.S., Nagarajan N. (2000) Formation and aging of incipient thin film wax-oil gels, Aiche J. 46, 5, 1059-1074.

12 Hernandez O., Hensley H., Sarica C., Brill J., Volk M., DelleCase E. (2003) Improvements in single-phase paraffin deposition modeling, SPE Annual Technical Conference and Exhibition, 5-8 October, Denver, Colorado, USA.

13 Zheng S., Saidoun M., Palermo T., Mateen K., Fogler H.S. (2017) Wax deposition modeling with considerations of nonNewtonian characteristics: Application on field-scale pipeline, Energy Fuels 31, 5, 5011-5023.

14 Wang W.D., Huang Q.Y., Wang C.H., Li S., Qu W.X., Zhao J.D., He M.Q. (2015) Effect of operating conditions on wax deposition in a laboratory flow loop characterized with DSC technique, J. Therm. Anal. Calorim. 119, 1, 471-485.

15 Henaut I., Betro B., Vinay G. (2019) Differential Scanning Calorimetry contribution to a better understanding of the aging of gelled waxy crude oils, Oil Gas Sci. Technol. - Rev. IFP Energies nouvelles 74, 16.

16 Ansaroudi H.R.J., Vafaie-Sefti M., Masoudi S., Behbahani T.J., Jafari H. (2013) Study of the morphology of wax crystals in the presence of ethylene-co-vinyl acetate copolymer, Pet. Sci. Technol. 31, 6, 643-651.
17 Hausen H. (1943) Darstellung des Warmeuberganges in Rohren durch verallgemeinerte Potenzbeziehungen, $Z$. VDI Beih. Verfahrenstech 4, 91-98.

18 Sieder E.N., Tate G.E. (1936) Heat transfer and pressure drop of liquids in tubes, Ind. Eng. Chem. 28, 12, 1429-1435.

19 Singh P., Venkatesan R., Fogler H.S., Nagarajan N.R. (2001) Morphological evolution of thick wax deposits during aging, Aiche J. 47, 1, 6-18.

20 Bergman T.L., Incropera F.P., DeWitt D.P., Lavine A.S. (2011) Fundamentals of heat and mass transfer, 3rd ed., John Wiley \& Sons, USA, pp. 120-132.

21 Cussler E.L., Hughes S.E., Iii W.J.W., Aris R. (1988) Barrier membranes, J. Membr. Sci. 38, 2, 161-174. doi: 10.1016/ S0376-7388(00)80877-7.

22 Lund H. (1998) Investigation of paraffin deposition during single-phase liquid flow in pipelines, Doctoral Thesis, University of Tulsa, USA.

23 Zhang X., Queimada A., Szczepanski R., Moorwood T. (2014) Modelling the shearing effect of flowing fluid and wax ageing on wax deposition in pipelines, Offshore Technology Conference, 25-28 March, Kuala Lumpur, Malaysia.

24 Yang X. (2006) Oil pipeline design and management, 2nd ed., China University of Petroleum Press, Dongying, China, pp. 92-93.

25 Wang Z. (2014) Study on gelling deposition behavior and control of oil-water two-phase system in cooling gathering 85 transportation, Northeast Petroleum University, Daqing, China. 